\section{Educação permanente e apoio matricial: formação, vivências e práticas dos profissionais dos Núcleos de Apoio à Saúde da Família e das equipes apoiadas}

\section{Continuing education and matrix support: training, experience, and practices of health professionals in the Centers for the Support of Family Health and the supported teams}

Educación permanente y apoyo matricial: formación, vivencias y prácticas de los profesionales de los Núcleos de Apoyo a la Salud de la Familia y de los equipos apoyados

\section{Resumo}

Este estudo objetivou compreender e analisar como os processos de educação permanente são vivenciados pelos profissionais dos Núcleos de Apoio à Saúde da Família (NASF) e das equipes de saúde da família (EqSF). Buscou ainda compreender como o apoio matricial, como estratégia de educação permanente, estava incorporado ao trabalho desses profissionais. Estudo de casos múltiplos, com abordagem qualitativa, realizado em seis municípios da Região Sudoeste da Bahia, Brasil, que contavam com NASF do tipo I. Foram realizadas entrevistas semiestruturadas com 43 profissionais do NASF e 40 com médicos e enfermeiros das equipes apoiadas. As entrevistas foram categorizadas e analisadas por meio da técnica da análise de conteúdo temática. Os resultados evidenciaram que as ações de educação permanente são insuficientes e inadequadas, com oferta de treinamentos esporádicos desenvolvidos por meio de metodologia tradicional de ensino. Evidencia-se a não institucionalidade da educação permanente como política nos municípios estudados. A formação sobre o apoio matricial e o processo de trabalho do NASF mostrou-se frágil para ambos os grupos, o que interfere na função de apoio e na gestão do cuidado. Foi evidenciada a diminuta atuação dos NASF como promotores de educação permanente para as equipes apoiadas.

Educação Permanente; Educação Profissional em Saúde Pública; Atenção Primária à Saúde; Saúde da Família; Relações Interprofissionais
José Patrício Bispo Júnior 1

Diane Costa Moreira 1

doi: 10.1590/0102-311X00108116

\author{
Correspondência \\ J. P. Bispo Júnior \\ Instituto Multidisciplinar em Saúde, Universidade Federal da \\ Bahia. \\ Rua Rio de Contas 58, Vitória da Conquista, \\ BA 45029-094, Brasil. \\ jpatricio@ufba.br \\ 1 Instituto Multidisciplinar em Saúde, Universidade Federal da \\ Bahia, Vitória da Conquista, Brasil.
}




\section{Introdução}

A organização e a estruturação dos novos modelos de atenção demandam desafios em diversas dimensões dos sistemas de saúde. Dentre esses, destaca-se a necessidade de reordenamento dos processos de trabalho em saúde, que exige cada vez mais a articulação de vários saberes e profissões, frente aos complexos problemas de saúde contemporâneos. Nesse contexto, a formação dos trabalhadores em saúde é um elemento essencial para que estes desempenhem o trabalho de forma articulada, embasados em evidências e socialmente comprometidos com a saúde de indivíduos e populações 1,2 .

No entanto, ainda verifica-se que a formação dos trabalhadores é um elemento crítico dos sistemas de saúde 3 . A formação em saúde no Brasil ainda está estruturada no modelo disciplinar de ensino e fundamentada nas ciências biológicas como fonte principal de conhecimento. Na melhor das hipóteses, treina técnicos competentes, porém, pouco comprometidos com as políticas públicas e as transformações sociais necessárias à promoção de condições de saúde adequadas. Na prática, os sujeitos formados nesse modelo revelam-se desconhecedores, quando não antagonistas do Sistema Único de Saúde (SUS) 4.

Esse não é um problema exclusivo do Brasil. A Comissão Independente Global para Educação dos Profissionais da Saúde alerta que as fragilidades da formação são comuns à maior parte dos países 5 . Dentre os principais entraves, destacam: incompatibilidade de competências para as necessidades dos usuários e da população; frágil trabalho em equipe; foco excessivamente técnico; limitação na compreensão dos contextos locais; orientação hospitalar predominante em detrimento da atenção primária; e fraca capacidade de liderança para melhorar o desempenho do sistema de saúde.

Para a referida comissão, três gerações de reformas educacionais caracterizam o avanço da formação profissional em saúde nos países ocidentais. A primeira, originada no início do século XX, instituiu um currículo baseado no saber científico. A segunda geração das reformas, iniciada em meados do século passado, introduziu inovações pedagógicas baseadas na problematização. Por último, a terceira geração é baseada nos sistemas e centrada nas populações. Busca melhorar o desempenho dos sistemas de saúde com foco no trabalho em equipe e na interprofissionalidade. Tem como finalidade orientar processos formativos voltados para a mobilização e articulação de conhecimentos, raciocínio crítico e conduta ética para a resolução dos problemas locais 5 .

No Brasil, a principal estratégia institucional para a qualificação dos profissionais do SUS é a Política Nacional de Educação Permanente em Saúde ${ }^{6}$. A educação permanente em saúde busca superar os tradicionais modelos de capacitação e de educação continuada, em que as atividades são pensadas e desenvolvidas alheias às necessidades reais dos serviços. A educação continuada é fundamentada na transmissão vertical de conhecimento com o intuito de atualizar novos enfoques, novos procedimentos ou novas tecnologias. Na maior parte das vezes, os processos educativos ocorrem com os trabalhadores isolados do contexto real do trabalho 7 .

Por sua vez, a educação permanente em saúde é caracterizada pela aprendizagem no trabalho e para o trabalho. Parte do pressuposto de que aprender e ensinar são fatores indissociáveis e se incorporam no cotidiano dos serviços e na interação entre os profissionais ${ }^{6}$. É uma concepção que norteia ações voltadas para o saber prático e transformador, pautada na interdisciplinaridade. Tem papel de destaque para a consolidação do SUS como processo social, frente ao protagonismo exercido pelos profissionais de saúde 8,9 .

No âmbito da atenção primária à saúde, as ações de educação permanente em saúde são consideradas essenciais e devem ser incorporadas na prática cotidiana dos serviços. A educação permanente das equipes de saúde da família (EqSF) deve ser embasada num processo pedagógico que propicie maior capacidade de análise, intervenção e autonomia para o desenvolvimento de práticas transformadoras 10 . Nesse contexto, o apoio matricial constitui uma importante ferramenta de trabalho e um mecanismo privilegiado de educação permanente em saúde. $\mathrm{O}$ apoio matricial está pautado na interprofissionalidade, trabalho em redes, atuação em território definido, compartilhamento de saberes, deliberação conjunta e cogestão. Além desses, também apresenta componente educador e formativo, uma vez que cria espaços de discussão, troca de saberes e reflexão para a prática 11,12 .

Com a criação dos Núcleos de Apoio à Saúde da Família (NASF), institucionalizou-se o apoio matricial como ferramenta de trabalho na saúde da família. O trabalho do NASF está estruturado em duas dimensões: retaguarda clínico-assistencial e apoio técnico-pedagógico. O NASF deve contribuir 
no processo de educação permanente das equipes apoiadas, na perspectiva de ampliação do cuidado e qualificação do trabalho. $\mathrm{O}$ apoio matricial possibilita o desenvolvimento de habilidades dos profissionais envolvidos, bem como o acesso a outras informações, à construção de novas estratégias de intervenção, à corresponsabilização e ao fortalecimento do trabalho interdisciplinar 13.

Por sua vez, deve ser destacado que o apoio matricial e as demais formas de organização do trabalho propostas pelo NASF são inovadoras $14 \mathrm{e}$ fundamentadas numa relação de horizontalidade entre os profissionais. Assim, esses novos arranjos e ferramentas de trabalho demandam uma nova compreensão do trabalho em saúde e um processo formativo que possibilite aos profissionais as habilidades para atuar conjuntamente frente aos desafios encontrados.

Diante desse contexto, o objetivo do estudo foi compreender e analisar como os processos de educação permanente são vivenciados pelos profissionais do NASF e das EqSF em municípios do Estado da Bahia, Brasil. Também buscou-se compreender como o apoio matricial, como estratégia de educação permanente, estava incorporado no trabalho desses profissionais.

\section{Método}

Trata-se de um estudo de casos múltiplos com níveis de análise imbricados, de abordagem qualitativa ${ }^{15}$. Conforme destacam Straus \& Corbin ${ }^{16}$, os estudos qualitativos possibilitam a penetração em uma realidade social de difícil apreensão, com capacidade de captar constâncias e variações na interação ao redor do fenômeno ou problema.

O cenário da pesquisa foi constituído por seis municípios integrantes do Núcleo Regional de Saúde da Região Sudoeste da Bahia, Brasil. Os mesmos foram selecionados com base em dois critérios: inicialmente foram identificados todos os que contavam com NASF do tipo I 10 em funcionamento há mais de um ano; em seguida, foram incluídos aqueles em que foi concedida a aquiescência da gestão municipal para a realização da pesquisa. Conforme observado na Tabela 1, a população dos mesmos variou entre 18.383 a 343.230 habitantes. Dois municípios (A e B) tinham uma equipe de NASF cada, dois outros (D e E) contavam com dois núcleos cada, o município $C$ tinha três NASF, e a cidade $F$ quatro equipes de NASF.

A pesquisa foi realizada com dois grupos de informantes: profissionais do NASF e profissionais das EqSF. Para ambos os grupos, o critério de inclusão estabelecido foi ter mais de seis meses de atuação na referida equipe. Foram contatados pessoalmente e convidados a participar todos os profissionais do NASF que atendiam o critério temporal descrito. Entre os membros da EqSF, excluíram-se os profissionais de nível técnico e a equipe de saúde bucal. Assim, foram entrevistados médicos e enfermeiros das equipes que recebiam apoio do NASF. Não ocorreu recusa, entre os elegíveis, quando convidados a participar da pesquisa. O período de realização das entrevistas foi entre junho de 2014 e fevereiro de 2015. O total de sujeitos e a distribuição por categoria e município são apresentados na Tabela 1.

As informações foram obtidas por meio de entrevistas semiestruturadas. As mesmas foram realizadas pelos dois autores deste artigo e por mais dois pesquisadores experientes e treinados. Nas entrevistas foram abordadas questões relativas à existência e participação em ações de educação permanente, bem como o desenvolvimento do apoio matricial como ferramenta de educação permanente em saúde. Utilizou-se um roteiro específico para os trabalhadores do NASF e outro para os profissionais da saúde da família, com adaptação das referidas questões às especificidades do trabalho das equipes. As entrevistas duraram em média de 40 minutos e o tempo total de gravação foi de 56 horas e 12 minutos. Essas entrevistas foram gravadas em aparelho de áudio digital e posteriormente transcritas. Como critério de certificação da fidedignidade das informações, cada entrevista depois de transcrita era ouvida, checada e, se necessário, corrigida por outro membro da equipe de pesquisa.

Os procedimentos analíticos foram realizados conforme a técnica proposta por Gibbs 17. As entrevistas foram codificadas e categorizadas, a fim de se identificar as ideias centrais do texto relativas à temática em estudo. Após leitura exaustiva das transcrições, foram estabelecidos códigos para identificar os conteúdos, que em algum sentido diziam respeito à mesma ideia teórica ou descritiva. Todas as entrevistas foram codificadas, atribuindo-se o mesmo código a todo recorte de texto que se referia a um conteúdo semelhante ou exemplificava algo de igual sentido ou significado. As categorias 
Tabela 1

Caracterização dos municípios e das equipes estudadas. Municípios participantes da pesquisa, Bahia, Brasil, 2015.

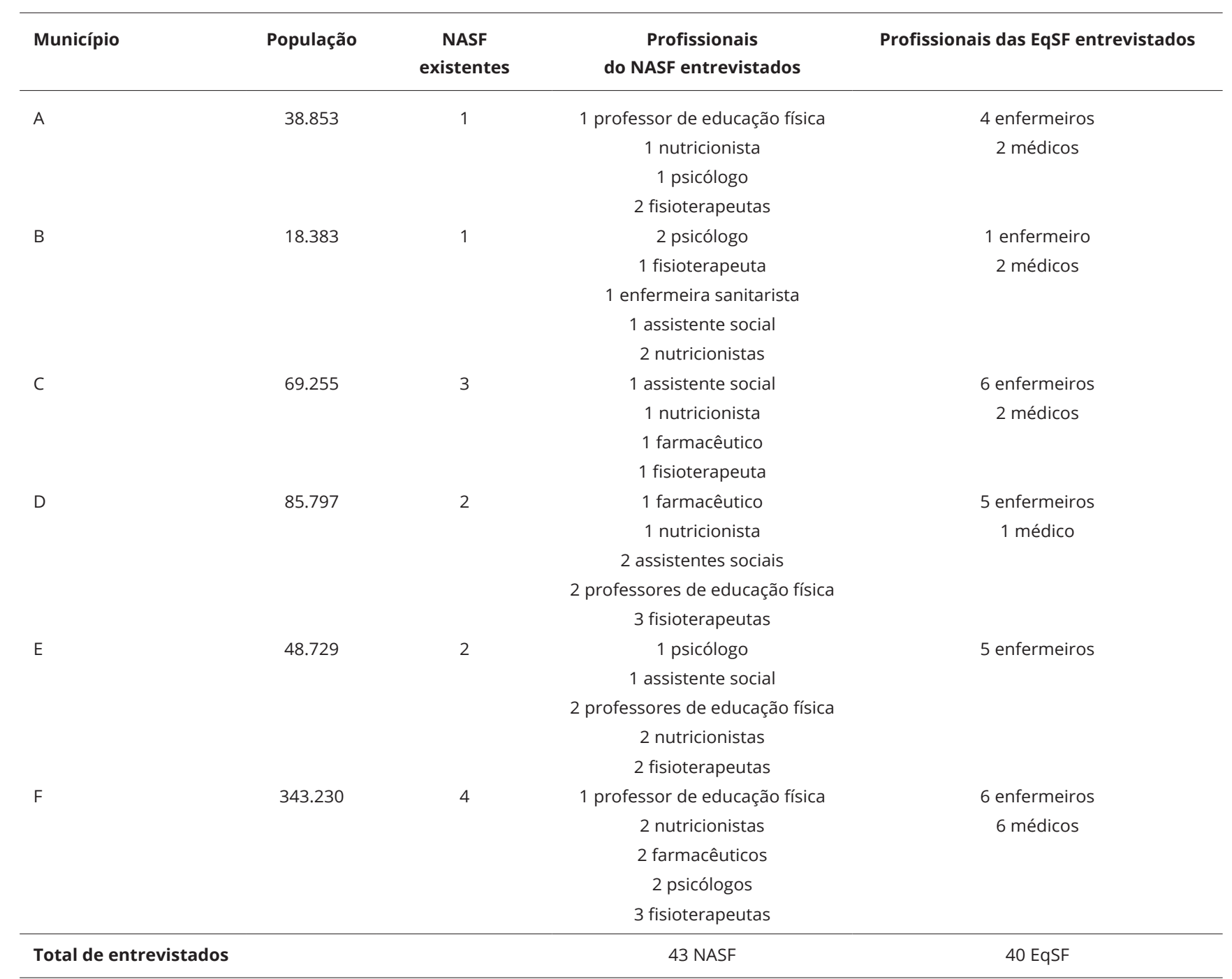

EqSF: equipes de saúde da família; NASF: Núcleos de Apoio à Saúde da Família.

Fontes: população (Instituto Brasileiro de Geografia e Estatística. Cidades@. http://www.cidades.ibge.gov.br/xtras/uf.php?lang=\&coduf=29\&search= bahia, acessado em 22/Jun/2016); número de NASF e profissionais entrevistados - dados da pesquisa.

e subcategorias temáticas foram estabelecidas com base no processo de aglutinação, refinamento e interconexão dos temas que mais se aproximavam e expressavam ideias analíticas semelhantes.

Foram observados os requisitos éticos da pesquisa com seres humanos, conforme estabelecido na Resolução CNS no 466/2012. O estudo foi submetido e aprovado pelo Comitê de Ética em Pesquisa (CEP) do Instituto Multidisciplinar em Saúde, Universidade Federal da Bahia (IMS/UFBA) sob parecer no 377.448/2013. Todos os participantes assinaram o Termo de Consentimento Livre e Esclarecido. 


\section{Resultados}

A análise dos resultados evidenciou três categorias temáticas: institucionalidade e vivências de educação permanente; temas das atividades educativas e a formação sobre o apoio matricial e NASF; e NASF como promotor de educação permanente. As mesmas são elencadas, com suas respectivas subcategorias, na Tabela 2.

\section{Institucionalidade e vivências de educação permanente}

Os resultados desta categoria evidenciaram que as ações educativas são insuficientes e inadequadas à formação dos profissionais. Nos seis municípios estudados, não foram observadas diferenças significativas no processo de formação dos trabalhadores da atenção primária à saúde. Os profissionais do NASF e das EqSF desvelaram que as atividades educativas desenvolvidas são escassas e estão aquém das necessárias para transformar as práticas de trabalho e fundamentar um cuidado resolutivo e humanizado.

"Não existem cursos, treinamentos. Infelizmente essa é uma realidade que eu e alguns outros colegas sentamos, discutimos o tempo todo e cobramos. Mas, infelizmente, isso não existe pra gente" (NASF 13, Assistente Social).

Além dos aspectos relacionados à frequência das atividades educativas, merece destaque a discussão sobre o modelo de formação desenvolvido. Observou-se no estudo a predominância de um modelo formativo baseado em cursos esporádicos e fragmentados. A educação profissional é desenvolvida por meio da oferta de capacitações e treinamentos, apoiada no saber biomédico e fundamentada em abordagem metodológica de transmissão unidirecional de informação. O principal propósito é de atualização de procedimentos, protocolos e rotinas, em geral baseando-se nas recomendações estabelecidas pelo Ministério da Saúde ou Secretaria Estadual de Saúde.

"Capacitações são raras. Eventualmente tem um ou outro. Teve o último agora que foi da implantação do e-SUS, né?! As fichas do e-SUS, foram esses cadastramentos novos. E assim... é eventualmente, uma vez ou outra que acontece" (EqSF 05, Médico).

Além da não institucionalidade da educação permanente em saúde como política nos municípios estudados, também evidenciaram-se dificuldades dos próprios profissionais, tanto do NASF quanto das equipes apoiadas, em compreender o processo formativo para além dos cursos ofertados de acordo com o modelo escolar.

"Eu, particularmente, tem muito tempo que eu participei de uma capacitação, de uma atividade assim de educação. Normalmente, o que a gente tinha era só um encontro dos profissionais, que não é uma educação, né? Era um encontro que era realizado trimestralmente com o NASF, pra gente ver como é que tava sendo realizada

Tabela 2

Categorias e subcategorias do estudo sobre educação permanente e apoio matricial em municípios da Bahia, Brasil.

\begin{tabular}{|c|c|}
\hline Categorias & Subcategorias \\
\hline \multirow[t]{3}{*}{ Institucionalidade e vivências de educação permanente } & • Frequência e regularidade das atividades educativas; \\
\hline & • Modelos de formação instituídos; \\
\hline & • Compreensões sobre educação permanente. \\
\hline \multirow[t]{2}{*}{ Temas das atividades educativas e formação sobre o apoio matricial } & - Temas das atividades educativas; \\
\hline & • Formação sobre processo de trabalho do NASF e apoio matricial. \\
\hline \multirow[t]{2}{*}{ NASF como promotor de educação permanente } & • Atuação do NASF na dimensão pedagógica; \\
\hline & - Qualificação dos trabalhadores do NASF para atuar na educação permanente. \\
\hline
\end{tabular}

NASF: Núcleos de Apoio à Saúde da Família. 
a atividade da gente aqui no município (....). Mas, educação permanente, de vir, de receber capacitação, não" (NASF 27, Nutricionista).

A compreensão que vigora entre os trabalhadores é que o modelo formativo deve acontecer a partir de cursos, treinamentos e capacitações com profissionais especialistas e em ambiente fora dos serviços de saúde. Mesmo os encontros de avaliação, em que se faziam debates sobre as práticas e atividades desenvolvidas, não eram percebidos pelos profissionais como espaço educativo e de aprimoramento do trabalho.

\section{Temas das atividades educativas e a formação sobre o apoio matricial e NASF}

$\mathrm{Na}$ análise sobre os temas e os conteúdos das atividades educativas vivenciadas, revelaram-se duas características principais: a formação focada em temas segmentados e específicos; e a diminuta formação sobre o método de apoio matricial e sobre processo de trabalho do NASF.

As atividades para ambas as equipes estavam voltadas para os agravos mais incidentes, os grupos populacionais prioritários e as áreas priorizadas pelo nível central de gestão. Os cursos e treinamentos, organizados ainda no modelo escolar, reproduzem as características de fragmentação do cuidado, do conteúdo e das políticas.

"A gente teve planejamento familiar é, teste do pezinho, testagem rápida de HIV e sífilis, foram alguns. De violência eu participei em Salvador, eu mesma fui, participei” (EqSF 21, Enfermeira).

"Quando é ofertado, a gente participa. Seja do que for, né? Teve um treinamento também com o pessoal da hanseniase, tuberculose e nós fomos orientados” (NASF 04, Fisioterapeuta).

No que tange à formação sobre matriciamento, a realidade estudada demonstra inexistência ou incipiente formação sobre esta ferramenta de trabalho. A maior parte dos discursos convergiu para ausência de qualquer atividade formativa, mesmo que pontual, sobre a lógica do apoio matricial ou sobre o processo de trabalho do NASF.

"O município nunca ofereceu uma capacitação pra gente relacionada ao NASF. Então assim, o que sabemos é porque corremos atrás, pesquisamos, questionamos com outros profissionais” (NASF 12, Assistente Social).

"Nós não somos incentivados quanto a isso, de ter cursos, de ter palestras, de ter oficinas. O máximo que nós tivemos foi quando a gente entrou, foi apresentado o que era o NASF pela coordenadora, meia hora, pronto, acabou" (NASF 14, Nutricionista).

As fragilidades na formação sobre matriciamento também foram reveladas entre os membros da equipe mínima. A maior parte dos enfermeiros e médicos das equipes investigadas afirmou não vivenciar nenhum tipo de formação sobre NASF ou apoio matricial.

"Eu só aqui nessa unidade eu tenho mais de dois anos, eu nunca recebi nenhum treinamento a respeito do NASF. Nunca, nunca, nunca” (EqSF 33, Enfermeiro).

"Eu acho péssimo não ter formação para o NASF, né? É porque trabalha com a gente, era pra tá somando, né? (...). Tem profissional aqui dentro que nem sabe pra quê que é NASF. Não sabe. Te garanto isso” (EqSF 33, Enfermeiro).

"Enfim, eu acho que o próprio NASF não foi capacitado para estar, imagine nós, né?, de Equipe de Saúde da Família" (EqSF 03, Enfermeiro).

Os achados suscitam a reflexão que tanto os trabalhadores dos NASF como os das equipes apoiadas devem estar devidamente sensibilizados e aptos para utilizarem as ferramentas do apoio matricial. O bom desempenho do trabalho do NASF não depende apenas da boa formação dos profissionais que o integram, mas também das EqSF. Nesse sentido, a reduzida formação sobre o apoio matricial, apresentada por ambos os grupos, compromete o trabalho entre as equipes e fragiliza a função de apoio.

\section{NASF como promotor de educação permanente}

Nos municípios estudados, foram observadas consideráveis fragilidades na dimensão pedagógica do trabalho do NASF. Foi consenso entre os profissionais do NASF a diminuta atuação em atividades de educação permanente em saúde com as equipes. A maior parte dos profissionais nunca desenvolveu qualquer atividade educativa com os profissionais de nível superior das EqSF, e aqueles que desenvolveram foi de forma pontual. 
"A gente deveria ter no cantinho da agenda, por mais que nós não queiramos fechar é... a agenda da educação permanente para as equipes. Mas ainda fazemos muito pouco, é muito pouco, viu?!" (NASF 22, Fisioterapeuta).

A reduzida atuação do NASF da dimensão pedagógica foi referendada pelos próprios médicos e enfermeiros. Esses destacaram não ser desenvolvida de forma regular as ações de Educação Permanente em Saúde promovidas pelo NASF.

"Comigo não, os profissionais do NASF não desenvolveram capacitações para a equipe" (EqSF 22, Médico).

"Esse apoio pedagógico ainda está realmente pouco. Existe muito pouco (...). Eles estão se encontrando, né?" (EqSF 11, Médico).

Foram ainda evidenciados os percalços da insuficiente formação do NASF como promotor de educação permanente em saúde. Os resultados desvelaram que os trabalhadores do NASF não se sentem preparados para atuar na dimensão pedagógica. Por conta da frágil formação vivenciada, os profissionais não possuem domínio sobre determinados aspectos do próprio trabalho do NASF e também do trabalho na atenção primária. Assim, destacam a insegurança de promover processos educativos com as EqSF frente à fragilidade da própria formação.

"Não tem. Tanto que, às vezes, foi questionado, falou assim: 'Ah, eu quero uma atualização'. Sim, mas e a minha, cadê? Porque, às vezes, a unidade cobra de você também, né? 'Ah, eu tô querendo uma atualização e tal'. Mas, na verdade a gente não tá recebendo essa atualização. Então, fica mais difícil você trabalhar atualização com um profissional, sendo que você mesmo não tá atualizado, né?" (NASF 25, Farmacêutico).

Merece destaque a inadequação dos processos pedagógicos pensados por ambos os grupos de profissionais como meio de educação permanente em saúde. Os resultados demonstram prevalecer uma compreensão vertical das ações educativas a serem desenvolvidas pelo NASF. As práticas formativas são pensadas apenas como cursos, treinamentos e capacitações que o NASF deve oferecer às EqSF. Como se os trabalhadores do NASF tivessem como função ensinar aos membros da equipe de referência determinadas técnicas e procedimentos.

\section{Discussão}

A qualificação técnica e o comprometimento político, humanístico e social dos profissionais de saúde são elementos essenciais para o bom desempenho do SUS. Isso reveste-se de especial importância em face à dissonância entre a missão do sistema de saúde e o modelo de ensino superior brasileiro 1,4. Conforme destaca Almeida Filho 1, a força de trabalho ideal para o atendimento no SUS não corresponde ao perfil dos profissionais que operam o sistema.

Nesse contexto, a educação permanente em saúde constitui-se em principal estratégia para qualificar a atuação dos trabalhadores em suas dimensões técnicas, políticas e sociais. Assim como os achados da presente investigação, diversos estudos demonstram a dificuldade de estados e municípios instituírem a educação permanente como política 9,18. Gerschman \& Schott 18 demonstram a dificuldade do Estado do Rio de Janeiro em implantar processos de educação permanente em saúde que conduzam ao aperfeiçoamento dos serviços de saúde e do atendimento à população. Em municípios de Santa Catarina, notou-se a ausência de tais processos entre os trabalhadores da atenção primária 9.

Também em outros países a formação dos profissionais apresenta fragilidades e incompatibilidades de competências frente às necessidades da população e aos desafios postos aos sistemas de saúde 19. Essa é uma realidade tanto dos países de baixa e média rendas 20,21 como em países de economia central 2,22 . O cenário internacional aponta cada vez mais a necessidade de interconexão entre os sistemas educacional e de saúde.

De acordo com Frenk et al. 5, o desafio posto é avançar de um modelo de aprendizagem informativo para um modelo formativo e daí para a aprendizagem transformadora. A aprendizagem informativa está centrada na aquisição de conhecimentos e competências, o objetivo é formar especialistas. A aprendizagem formativa está centrada na aquisição de valores, o objetivo é formar profissionais éticos. Por sua vez, a aprendizagem transformadora está centrada no desenvolvimento de atributos de liderança, o objetivo é produzir agentes esclarecidos de mudança, com capacidade de articular informações e conhecimentos diversos para interferir em contextos específicos.

Nos municípios estudados, o modelo de formação desenvolvido é fundamentado na lógica da educação continuada. Nesse contexto, torna-se importante refletir sobre as diferenças das abordagens e 
práticas de educação continuada e educação permanente. A educação continuada baseia-se em ações de caráter pontual, fragmentado e com metodologias tradicionais de ensino ${ }^{8}$. O que se preconiza é a aquisição de saberes e competências técnico-profissionais e disciplinares, baseada na racionalidade instrumental de atualização profissional, centrada na execução de procedimentos e rotinas e com o objetivo de manter a normatividade das ações de saúde 23.

Diante da complexidade do trabalho em saúde e dos múltiplos determinantes sociais imbricados no processo saúde/doença/cuidado, o saber técnico-científico e a racionalidade instrumental são inapropriados para a formação dos trabalhadores. A literatura da área destaca a importância da educação permanente em saúde fundamentada na aprendizagem significativa, centrada no exercício cotidiano do trabalho e na valorização do ambiente profissional como lócus privilegiado de fonte de conhecimento 8 .

Nesse sentido, além da frequência com que as atividades são desenvolvidas e do espaço em que isto ocorre, a magnitude da educação permanente em saúde constitui-se em seu caráter transformador da realidade dos serviços e das necessidades da população. Enquanto a educação continuada pressupõe a reprodução de conhecimentos, a educação permanente em saúde caracteriza-se como prática fecunda de produção de saberes e novos conhecimentos. Baseando-se na problematização das questões reais e cotidianas, busca-se a transformação das práticas e das realidades vivenciadas.

A própria dificuldade de compreensão, entre os trabalhadores, sobre o processo educativo, pode ser um fator de forte interferência para a não institucionalidade da política de educação permanente em saúde. Uma compreensão ampliada da educação permanente em saúde pode contribuir para o desenvolvimento de mecanismos de pressão aos órgãos gestores e às instâncias deliberativas, em face de outra política de educação profissional. Também, o fato de perceber-se como sujeito do seu próprio aprendizado potencializa a condução de mudanças cotidianas e ascendentes.

O processo formativo restrito a um conjunto de conteúdos, muitas vezes com enfoque biologicista e com ênfase na prescrição de procedimentos e protocolos, contribui para a consolidação de um modelo de atenção à saúde fragmentado e descontextualizado da realidade social. Ou seja, uma formação profissional com tais características só reforça o desenvolvimento de ações em saúde fragmentadas. Essa talvez seja uma das principais contradições das ações de educação desenvolvidas. A formação dos profissionais deveria ter como propósito principal a transformação da práxis e dos sistemas de saúde. No entanto, a depender de como seja estruturada e desenvolvida, a educação dos trabalhadores pode ser um mecanismo de formação de meros executores de procedimentos, pouco comprometidos com o SUS e com as transformações sociais.

Os achados deste estudo merecem atenção por sua similaridade com outros cenários. Santos et al. 24, em pesquisa com mais de 14 mil EqSF de todos os estados brasileiros, identificaram que apenas 22\% das equipes recebem apoio para a reorganização do processo de trabalho. Sobre essa realidade, Miccas \& Batista 8 destacam que a organização educacional com base em um modelo disciplinar e fragmentado dificulta a formação de profissionais críticos, reflexivos e constitui empecilho para a integralidade do cuidado. Como muitos dos profissionais que atuam no NASF e nas EqSF possuem, por conta do modelo de formação universitária, visão fragmentada em relação ao cuidado, o déficit da educação permanente em saúde implica a qualidade da atenção prestada, seja ela individual ou coletiva 25 .

No que tange ao apoio matricial, os formuladores desta proposta destacam que este é ao mesmo tempo metodologia para a gestão do trabalho e arranjo organizacional. Como método de trabalho, é um conjunto de conceitos sobre o modo de desenvolver o trabalho interprofissional em cogestão e de maneira compartilhada. Como arranjo organizacional, é caracterizado como lugar estrutural com base no qual se desempenha a função de apoio 11,12 .

Os resultados da pesquisa demonstraram a frágil formação sobre o apoio matricial tanto para os profissionais do NASF como para os trabalhadores das EqSF. Tais fragilidades sugerem implicações para o trabalho no âmbito da atenção primária à saúde, visto que esta ferramenta de trabalho tem como propósitos alargar as intervenções em direção à clínica ampliada, superar a lógica dos encaminhamentos que fragmenta o cuidado, e potencializar a integração dialógica entre diferentes especialidades e profissões 12 .

Vale destacar que o arranjo do apoio matricial é uma construção genuinamente brasileira. No cenário internacional a discussão está centrada na troca de conhecimento entre profissionais e no atendimento compartilhado, especialmente no cuidado de doenças crônicas, como observado em 
experiências do Canadá 26 e do Reino Unido 27. Na análise empreendida por Oliveira \& Campos 12, observou-se que os congêneres da literatura internacional para trabalho interprofissional são cuidado colaborativo (collaborative care) e cuidado compartilhado (shared care). Embora as evidências ainda sejam tímidas, os principais fatores que potencializam o cuidado colaborativo em outros países são a comunicação entre os profissionais, a existência de tecnologias de informações ágeis e a estrutura organizacional do sistema de saúde 27,28.

No Brasil, a ferramenta do apoio matricial e a lógica de trabalho do NASF diferem consideravelmente das práticas e das relações tradicionais estabelecidas entre médicos e enfermeiros da saúde da família e os profissionais de outras formações. São novas formas de organizar o trabalho, novos parâmetros nas relações interprofissionais e nova forma de responsabilizar-se pelos usuários. No entanto, ainda predomina no país um modelo de formação em que cada profissional é responsável por uma parte do corpo do indivíduo, sem a devida abordagem da importância do trabalho interdisciplinar 25 .

Tanto os trabalhadores do NASF como das EqSF demostraram desconhecimento e frágil formação sobre o apoio matricial. No entanto, esse apoio a ser desenvolvido não se sustenta apenas na busca da intervenção de um especialista, em que, muitas vezes, aquele que encaminha se desresponsabiliza do cuidado. É um tipo de apoio que aumenta a responsabilidade daquele que é apoiado e faz este vincular-se ainda mais ao usuário, família ou comunidade. Assim, os profissionais das EqSF necessitam ser qualificados para ser apoiados. E para isso é imprescindível que eles também vivenciem ações de educação permanente em saúde sobre o matriciamento.

Um processo formativo frágil para o apoio matricial gera incompreensões, expectativas irreais sobre o trabalho do outro e conflitos entre aqueles que deveriam ser parceiros. Conforme assinalam Santos et al. 24, a consolidação do apoio matricial como indutor de mudança no modelo de atenção à saúde ainda está em processo e precisa ser aprimorado. É importante compreender, no entanto, que a mudança na lógica de trabalho proposta pelo apoio matricial não ocorre automaticamente, demanda tempo e comprometimento e deve ser fortemente fundamentada nos processos de educação permanente em saúde.

De acordo com as diretrizes do NASF, o suporte técnico-pedagógico às equipes apoiadas deve constituir-se em ação prioritária do trabalho dos núcleos. Ao NASF cabe desenvolver ações de educação permanente em saúde às EqSF, com o propósito de contribuir com o aumento da capacidade de cuidado das equipes. Deve compartilhar saberes e práticas para a resolução de problemas e o manejo de situações complexas e desafiadoras. Cabe ao NASF, inclusive, compartilhar ações por meio de transferência de tecnologia, seja ela dura, leve dura ou leve, de forma cooperativa e horizontal. Ou seja, prestar o devido apoio pedagógico que progressivamente deve produzir mais autonomia para as equipes apoiadas 29 .

No entanto, a realidade observada no estudo demonstra a diminuta atuação do NASF no apoio pedagógico às equipes. Ao se analisar os elementos que contribuem para a exígua prática formativa, identificou-se que os profissionais do NASF não estão preparados e sentem-se inseguros para o desenvolvimento das atividades formativas.

Realidade semelhante foi observada em outros cenários. Silva et al. 30 identificaram que ainda persistem fragilidades para a atuação nas atividades educativas do NASF com as equipes. Os autores identificaram que um dos fatores que dificultam o desenvolvimento da ação pedagógica pelos apoiadores é a frágil formação dos próprios profissionais do NASF. Esses, muitas vezes, não possuem as devidas competências e habilidades para o trabalho em equipe, o vínculo e o acolhimento, imprescindíveis para as ações de matriciamento. Também Souza et al. 31 destacam a necessidade de aprimoramento no processo formativo dos profissionais do NASF para que estes possam atuar de maneira qualificada na dimensão pedagógica.

As compreensões sobre o que vem a se constituir em apoio pedagógico, também se mostraram como fatores intervenientes da ação do NASF. Essa dimensão do trabalho é percebida, conforme pressupostos de Freire 32, pela lógica bancária da educação. Como se os profissionais do NASF devessem realizar depósitos de conteúdo ou ensinar determinados procedimentos aos profissionais das equipes apoiadas, que seriam meros receptores. Essa visão simplista, restrita e vertical da função de apoio necessita ser superada e transformada em direção a uma abordagem mais emancipatória da formação. A dimensão pedagógica do NASF deve ser pensada como relação dialógica de interação-aprendiza- 
gem, em que todos os envolvidos aprendem e ao mesmo tempo ensinam com base na interação dos diversos núcleos de saber.

Nesse contexto, o apoio matricial mostra-se como espaço privilegiado para as práticas de ensinoaprendizagem. As atividades do apoio pedagógico podem se efetivar nos encontros em que ocorram atividades compartilhadas entre NASF e EqSF ou em que aconteça a discussão de casos individuais e coletivos 14. Assim, as ações de educação permanente em saúde podem ocorrer em todos os momentos de interação entre apoiadores e equipes de referência. Para isso, é também necessária a superação das relações hierárquicas entre as profissões e o estabelecimento de práticas horizontalizadas, inerentes aos processos dialógicos.

Como todo processo dialógico, a educação permanente não constitui-se em via de mão única. O apoio pedagógico deve ser tanto do NASF para com as EqSF, como das equipes para com o NASF. Conforme se observou em estudo realizado na cidade de São Paulo, os profissionais do NASF também se sentem matriciados pelas EqSF, sobretudo pelos conhecimentos referentes ao território e às demandas das comunidade 14. Isso porque o apoio matricial tem a função de compartilhar conhecimento e construir conjuntamente possibilidades de intervenção, e não de ditar, sozinho, as regras do jogo 13 . Para Oliveira \& Campos 12, o apoio matricial é também uma forma de reconstrução de si mesmo: no mesmo tempo em que presta apoio pedagógico também se é apoiado. Ou como destacam Abrahão \& Merhy 33: formar é estar em formação, é produção, é produzir-se. Processo que se torna imanente às multiplicidades do encontro. Com o encontro, aqueles que se encontram estão em produção.

\section{Considerações finais}

O estudo evidenciou a ausência da educação permanente como política institucional. As ações de formação desenvolvidas ainda estão aquém do que se espera para as transformações desejadas no âmbito da saúde. O formato de educação observado era realizado de maneira pontual e fragmentada, prevalecendo o uso de metodologias tradicionais, verticalizadas e conduzidas por especialistas com pouca ou nenhuma conexão com a realidade local dos serviços.

Sobre o apoio matricial, demonstrou-se que os profissionais do NASF e das EqSF não vivenciam a formação adequada sobre esta ferramenta e sobre o seu próprio processo de trabalho. Outra questão a considerar é a frágil atuação do NASF como promotor de educação permanente às EqSF. O que remete também ao modelo de apoio pedagógico a ser desenvolvido, uma vez que ambos os grupos ainda trazem uma visão de educação profissional como capacitações conteudistas e verticalizadas.

Os principais achados da investigação suscitam a reflexão a respeito das implicações da formação inadequada sobre o desenvolvimento dos serviços e a qualidade da atenção prestada. Diante disso, destaca-se a necessidade da institucionalização da política de educação permanente como parte integrante e inerente ao trabalho na saúde da família.

Destarte, é importante considerar a necessidade da sensibilização de gestores e profissionais para assumirem a educação permanente como ação inerente e não dissociada da atenção à saúde. Sugere-se também um maior nível de articulação regional e o envolvimento da secretaria estadual de saúde, por meio dos núcleos regionais de saúde. Diante das limitações, especialmente dos municípios de pequeno porte, é importante existir um ente estadual que promova a articulação regional e propicie apoio aos respectivos municípios. 


\section{Colaboradores}

J. P. Bispo Júnior contribuiu na concepção do projeto; coleta, análise e interpretação dos dados; redação e revisão crítica do artigo e aprovação da versão final. D. C. Moreira colaborou na coleta, análise e interpretação dos dados; redação e revisão crítica do artigo e aprovação da versão final.

\section{Agradecimentos}

À Fundação de Amparo à Pesquisa do Estado da Bahia (FAPESB) pelo apoio concedido por meio do Programa de Pesquisa para o SUS (PPSUS-BA), Edital 20/2013.

\section{Referências}

1. Almeida Filho N. Higher education and health care in Brazil. Lancet 2011; 377:1898-900.

2. Bozorgmehr K, Saint VA, Tinnemann P. The 'global health' education framework: a conceptual guide for monitoring, evaluation and practice. Global Health 2011; 7:1-12.

3. Pinto ICM, Teixeira CF. Formulação da política de gestão do trabalho e educação na saúde: o caso da Secretaria Estadual de Saúde da Bahia, Brasil, 2007-2008. Cad Saúde Pública 2011; 27:1777-88.

4. Almeida Filho N. Contextos, impasses e desafios na formação de trabalhadores em Saúde Coletiva no Brasil. Ciênc Saúde Coletiva 2013; 18:1677-82.

5. Frenk J, Chen L, Bhutta ZAB, Cohen J, Crisp $\mathrm{N}$, Evans T, et al. Health professionals for a new century: transforming education to strengthen health systems in an interdependent world. Lancet 2010; 376:1923-58.
6. Ministério da Saúde. Portaria GM/MS no 1.996 , de 20 de agosto de 2007. Dispõe sobre as diretrizes para a implementação da Política Nacional de Educação Permanente em Saúde e dá outras providências. Diário Oficial da União 2007; 22 ago.

7. Pierantoni CR, Varella TC, Monteiro VO, Santos MR, França T. Reconfigurando perfis profissionais: a especialização em saúde da família. In: Pierantoni CR, Vianna ALD, organizadores. Educação e saúde. São Paulo: Editora Hucitec; 2010. p. 224-39.

8. Miccas FL, Batista SHSS. Educação permanente em saúde: metassíntese. Rev Saúde Pública 2014; 28:170-85.

9. Tesser CD, Garcia AV, Vendruscolo C, Argenta CE. Estratégia saúde da família e análise da realidade social: subsídios para políticas de promoção da saúde e educação permanente. Ciênc Saúde Coletiva 2011; 16:4295-306. 
10. Departamento de Atenção Básica, Secretaria de Atenção à Saúde. Ministério da Saúde. Política Nacional de Atenção Básica. Legislação em saúde. Brasília: Ministério da Saúde; 2012. (Série E. Legislação em Saúde).

11. Campos GWS, Figueiredo MD, Pereira Júnior N, Castro CP. A aplicação da metodologia Paideia no apoio institucional, no apoio matricial e na clínica ampliada. Interface (Botucatu, Online) 2014; 18 Suppl 1:S983-95.

12. Oliveira MM, Campos GWS. Apoios matricial e institucional: analisando suas construções. Ciênc Saúde Coletiva 2015; 20:229-38.

13. Ballarin MLGS, Blanes LS, Ferigato SH. Apoio matricial: um estudo sobre a perspectiva de profissionais da saúde mental. Interface Comun Saúde Educ 2012; 16:767-78.

14. Barros JO, Gonçalves RMA, Kaltner RP, Lancman S. Estratégia do apoio matricial: a experiência de duas equipes do Núcleo de Apoio à Saúde da Família (NASF) da cidade de São Paulo, Brasil. Ciênc Saúde Coletiva 2015; 20:2847-56.

15. Yin RK. Estudo de caso: planejamento e métodos. 5a Ed. Porto Alegre: Bookman; 2015.

16. Straus A, Corbin J. Pesquisa qualitativa: técnicas e procedimentos para o desenvolvimento de teoria fundamentada. $2^{\text {a }}$ Ed. Porto Alegre: Editora Artmed; 2008.

17. Gibbs G. Análise de dados qualitativos. Porto Alegre: Editora Artmed; 2009.

18. Gerschman S, Schott M. Os percalços da política de educação permanente em saúde no Estado do Rio de Janeiro: dilemas institucionais no âmbito estadual. In: Pierantoni CR, Vianna ALD, organizadores. Educação e saúde. São Paulo: Editora Hucitec; 2010. p. 204-23.

19. Maeseneer J, Aarendonk D. European forum for primary care. Eur J Gen Pract 2012, 18:127-8

20. Campbell J, Buchan J, Cometto G, David B, Dussault G, Fogstad H, et al. Human resources for health and universal health coverage: fostering equity and effective coverage. Bull World Health Organ 2013; 91:853-63.

21. Gaspard J, Yang C. Training needs assessment of health care professionals in a developing country: the example of Saint Lucia. BMC Med Educ 2016; 16:1-6.

22. Lindsay E, Wooltorton E, Hendry P, Williams $\mathrm{K}$, Wells G. Family physicians' continuing professional development activities: current practices and potential for new options. Can Med Educ J 2016; 7:e38-46.

23. Silva JAM, Peduzzi M. Educação no trabalho na atenção primária à saúde: interfaces entre a educação permanente em saúde e o agir comunicativo. Saúde Soc 2011; 20:1018-32.

24. Santos AF, Machado ATGM, Reis CMR, Abreu DMX, Araújo LHL, Rodrigues SC, et al. Apoio institucional e matricial e sua relação com o cuidado na atenção básica à saúde. Rev Saúde Pública 2015; 49:54.
25. Anjos KF, Meira SS, Ferraz CEO, Vilela ABA, Boery RNSO, Sena ELS. Perspectivas e desafios do Núcleo de Apoio à Saúde da Família quanto às práticas em saúde. Saúde Debate 2013; 37:672-80.

26. Madarnas Y, Joy A, Verma S, Sehdev S, Lam W, Sideris L. Models of care for early-stage breast câncer in Canada. Curr Oncol 2011; 18 Suppl 1:S10-9.

27. Sheaff R, Halliday J, Ovretveit J, Byng R, Exworthy M, Peckham S, et al. Integration and continuity of primary care: polyclinics and alternatives - a patient-centred analysis of how organisation constrains care co-ordination. Southampton: NIHR Journals Library; 2015.

28. Foy R, Hempel S, Rubenstein L, Suttorp M, Seelig M, Shanman R, et al. Meta-analysis: effect of inte $\neg$ ractive communication between collaborating primary care physicians and specialists. Ann Intern Med 2010; 152:247-58.

29. Departamento de Atenção Básica, Secretaria de Atenção à Saúde, Ministério da Saúde. Núcleo de Apoio à Saúde da Família: ferramentas para a gestão e para o trabalho cotidiano. v. 1 . Brasília: Ministério da Saúde; 2014. (Cadernos de Atenção Básica, 39).

30. Silva ATC, Aguiar ME, Winck K, Rodrigues KGW, Sato ME, Grisi SJFE, et al. Núcleos de Apoio à Saúde da Família: desafios e potencialidades na visão dos profissionais da Atenção Primária do Município de São Paulo, Brasil. Cad Saúde Pública 2012; 28:2076-84.

31. Souza MC, Bomfim AS, Souza JN, Franco TB. Fisioterapia e Núcleo de Apoio à Saúde da Família: conhecimento, ferramentas e desafios. Mundo Saúde 2013; 27:176-84.

32. Freire P. Pedagogia da autonomia: saberes necessários à prática educativa. 53a Ed. Rio de Janeiro: Paz e Terra; 2016.

33. Abrahão AL, Merhy EE. Formação em saúde e micropolítica: sobre conceitos-ferramentas na prática de ensinar. Interface (Botucatu, Online) 2014; 18:313-24. 


\section{Abstract}

This study aimed to understand and analyze how processes of continuing education are experienced by professionals in the Centers for the Support of Family Health (NASF) and family health teams. The aim was also to understand how matrix support as a strategy for continuing education was incorporated into the work of these professionals. This was a multiple case study with a qualitative approach in six municipalities in southeast Bahia State, Brazil, which had type-I NASF. Semi-structured interviews were held with 43 NASF professionals and 40 with physicians and nurses from the supported teams. The interviews were categorized and analyzed using thematic content analysis. The results showed that the activities in continuing education are insufficient and inadequate, with a supply of sporadic training developed with a traditional teaching methodology. Continuing education had not been institutionally consolidated in the six municipalities. Training in matrix support and the work process in the NASF proved weak for both groups, which interfered in the support function and management of care. The study revealed the limited action of NASF as promotors of continuing education for the supported teams.

Continuing Education; Public Health Professional Education; Primary Health Care; Family Health; Interprofessional Relations

\section{Resumen}

Este estudio tuvo como meta comprender y analizar cómo se viven los procesos de educación permanente por parte de los profesionales de los Núcleos de Apoyo a la Salud de la Familia (NASF) $y$ de los equipos de salud de la familia (EqSF). Se buscó incluso comprender cómo el apoyo matricial, como estrategia de educación permanente, estaba incorporado al trabajo de estos profesionales. Es un estudio de casos múltiples, con un enfoque cualitativo, realizado en seis municipios de la región sudoeste de Bahía, Brasil, que contaban con NASF del tipo I. Se realizaron entrevistas semiestructuradas a 43 profesionales del NASF y 40 con médicos y enfermeros de los equipos apoyados. Las entrevistas fueron categorizadas y analizadas mediante la técnica el análisis de contenido temático. Los resultados evidenciaron que las acciones de educación permanente son insuficientes e inadecuadas, con una oferta de formación esporádica, desarrollada mediante una metodología tradicional de enseñanza. Se evidencia la no institucionalidad de la educación permanente como política en los municipios estudiados. La formación sobre el apoyo matricial y el proceso de trabajo del NASF se mostró frágil para ambos grupos, lo que interfiere en la función de apoyo y en la gestión del cuidado. Se evidenció una escasa actuación de los NASF como promotores de educación permanente hacia los equipos apoyados.

Educación Continua; Educación en Salud Pública Profesional; Atención Primaria de Salud; Salud de la Familia; Relaciones Interprofesionales
Recebido em 22/Jun/2016

Versão final reapresentada em 04/Nov/2016

Aprovado em 28/Nov/2016 